\title{
Porosidade de aeração de um Latossolo Vermelho e rendimento de trigo em plantio direto escarificado
}

\author{
Air-filled porosity in Latosol and wheat grain yield under no-tillage chiseled \\ Vilson Antonio Klein ${ }^{\text {* }}$ Márcio Luis Vieira' ${ }^{\text {II }}$ Fabio Fernando Durigon ${ }^{\text {II }}$ \\ João Paulo Massing ${ }^{\text {III }}$ Fernando Fávero ${ }^{\text {III }}$
}

\section{RESUMO}

\begin{abstract}
Proporcionar condições ótimas ao desenvolvimento das plantas deve ser um dos objetivos do manejo do solo. O sistema plantio direto é um manejo conservacionista por excelência, mas tem apresentado problemas de compactação, afetando o desenvolvimento e à produtividade das culturas. A escarificação esporádica do solo nessas áreas tem-se apresentado como uma alternativa para minimizar os efeitos negativos do aumento da sua densidade. Neste estudo, avaliouse a densidade do solo, a porosidade total e de aeração, a densidade máxima e a relativa do solo e o rendimento de grãos de trigo num Latossolo em duas áreas: plantio direto há 6 anos (PD) e plantio direto escarificado (PDE). Durante todo o ciclo da cultura do trigo, monitorou-se o potencial de água no solo por meio de sensores eletrônicos e "datalogger". A escarificação esporádica do solo sob sistema plantio direto diminuiu (5\%) a densidade e a densidade relativa do solo, aumentou a porosidade total e alterou a dinâmica da água no solo, proporcionou maior volume de poros livres de água (7,6\%) durante todo o ciclo da cultura do trigo e aumentou significativamente o rendimento de grãos $\left(682 \mathrm{~kg} \mathrm{ha}^{-1}\right)$.
\end{abstract}

Palavras-chave: compactação do solo, plantio direto, escarificação, densidade relativa.

\section{ABSTRACT}

The soil management should be aimed at providing optimal conditions for plant growth and development. No-tillage is a quintessential conservative system; however, it has caused compaction, thus affecting crop development and yield. Sporadic soil chiseling in these areas has been used as an alternative to minimize the negative effects of an increase in bulk density. The soil bulk density, total porosity, air-filled porosity, maximum density, relative density, and wheat grain yield of an oxisol were assessed in two areas: under no- tillage for 6 years and under no tillage chiseled. Soil water potential was monitored throughout the wheat crop cycle by using electronic sensors and a datalogger. Results show that sporadic chiseling of the soil under no-tillage reduced soil density and relative density by $5 \%$, increased total porosity and changed the soil water dynamics, resulting in a higher volume of water-free pores (7.6\%) throughout the wheat crop cycle, remarkably increasing grain yield $\left(682 \mathrm{~kg} \mathrm{ha}^{-1}\right)$.

Key words: soil compaction, no-tillage, chiseling, relative bulk density.

\section{INTRODUÇÃO}

A produção de alimentos é um dos grandes desafios da humanidade. Tecnologias cada vez mais modernas têm sido adotadas para obter produção em quantidade e qualidade suficientes para alimentar a população do planeta. Na busca desse objetivo, a ação do homem tem afetado consideravelmente o sistema solo/água/planta. Algumas dessas ações são positivas, como o aumento do rendimento das culturas em função da melhoria nas condições de desenvolvimento (fertilização e irrigação) e proteção das plantas (eficiência dos defensivos e tecnologia de aplicação), outras são negativas, como a degradação do solo e a poluição do ambiente e dos recursos hídricos.

O solo é um dos principais suportes da produção agrícola e o seu comportamento é regido por um complexo conjunto de fatores físicos, químicos e biológicos, submetidos à ação do clima, que interagem

IFaculdade de Agronomia e Medicina Veterinária (FAMV), Universidade de Passo Fundo (UPF), CP 611, 99001-970, Passo Fundo, RS, Brasil. E-mail: vaklein@upf.br. *Autor para correspondência.

IC Curso de Pós-graduação em Agronomia, FAMV/UPF, Passo Fundo, RS, Brasil.

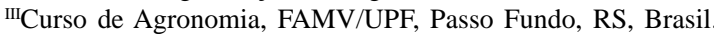


e tendem ao equilíbrio. O homem, através das práticas agrícolas, interfere neste sistema, alterando-o, e afetando as propriedades físicas do solo importantes para o desenvolvimento das plantas e a preservação dos recursos hídricos (KLEIN, 1998).

As alterações que ocorrem na estrutura do solo, evidenciadas por modificações de sua densidade, afetam a resistência mecânica do solo à penetração, a porosidade total, a distribuição do diâmetro dos poros, a porosidade de aeração, a armazenagem e a disponibilidade de água as plantas, bem como, a dinâmica da água na superfície e no perfil do solo (KLEIN, 1998; CAMARA \& KLEIN, 2005a; VIEIRA, 2006).

Entre as alterações ocasionadas pela compactação, especificamente em regiões úmidas, uma delas é a redução na porosidade de aeração. O efeito negativo desta sobre o desenvolvimento das plantas ocorre por deficiência na difusão de gases junto ao sistema radicular das plantas (STEPNIEWSKI et al., 1994). Alguns desses efeitos, segundo SOJKA(1992), são o fechamento dos estômatos, o murchamento das plantas, a necrose das raízes, a obstrução do xilema à água e o desbalanço nutricional e hormonal das plantas.

A dinâmica dos gases no solo ainda é pouco estudada, pois, o estudo físico-analítico dos processos de transferência dos mesmos no solo é bastante complexo (REICHARDT \& TIMM (2004). Arenovação de oxigênio no solo vem da atmosfera superior, por difusão, em solução com água ou por fluxo de massa, sendo este o principal processo responsável pela transferência desse no solo.

O trigo é uma cultura importante e o seu período de cultivo no Rio Grande do Sul apresenta balanço hídrico positivo, isto é, precipitação maior do que evapotranspiração, sendo comum a ocorrência de período com elevado teor de água no solo e, por conseqüência, reduzida aeração. Nessa condição, o rendimento do trigo, bem como o teor de proteína nos grãos é diminuído, especialmente em solos compactados (SOJKA, 1992).

Comumente é referido que valores menores que $0,1 \mathrm{~m}^{3} \mathrm{~m}^{-3}$ de poros livre de ar impõem limitação ao pleno desenvolvimento do sistema radicular das plantas (ERICKSON, 1982; TORMENA et al., 1998). No entanto, pouco é discutido sobre a concentração de $\mathrm{O}_{2}$ e $\mathrm{CO}_{2}$ nessa porosidade, que afeta de forma diferenciada o desenvolvimento das plantas. Além disso, existe a influência da variabilidade espacial e temporal desse parâmetro, podendo, em curtos intervalos de tempo, restringir o desenvolvimento radicular em camadas específicas, e as outras camadas com aeração adequada compensar essa limitação (JONG VAN LIER, 2001). A determinação de limites mínimos para porosidade de aeração é, portanto, bastante complexa. GLINSKI \& LIPIEC (1990) apresentam valores limitantes para cultura do trigo desde 0,021 até $0,145 \mathrm{~m}^{3} \mathrm{~m}^{-3}$.

Sistemas conservacionistas de manejo do solo, com destaque ao sistema plantio direto, têm sido adotados em grande escala, principalmente na região Sul do Brasil. Essa prática de manejo conservacionista do solo têm ocasionado mudanças significativas nas propriedades do solo, sendo a principal delas o aumento da densidade (BOLLER, 1990; KLEIN et al., 1995) com conseqüente redução da porosidade total e de aeração, além do aumento da resistência mecânica do solo à penetração (CAMARA \& KLEIN, 2005b; VIEIRA, 2006).

A escarificação esporádica do solo sob plantio direto tem se apresentado como uma alternativa viável para minimizar as limitações físicas ao crescimento das plantas. Alguns trabalhos têm demonstrado aumentos significativos no rendimento das culturas em solos sob plantio direto escarificado (CAMARA \& KLEIN, 2005b; VIEIRA, 2006).

O objetivo deste trabalho foi avaliar as alterações nas propriedades físico-hídricas do solo e o rendimento de trigo em um Latossolo Vermelho sob plantio direto e plantio direto escarificado.

\section{MATERIAL E MÉTODOS}

O experimento foi conduzido em um Latossolo Vermelho distrófico típico (STRECK et al., 2002), composição granulométrica média de $469 \mathrm{~g} \mathrm{~kg}^{-1}$ de argila, $118 \mathrm{~g} \mathrm{~kg}^{-1}$ de silte e $412 \mathrm{~g} \mathrm{~kg}^{-1}$ de areia, com variação em profundidade não superior a $4 \%$, relevo ondulado e substrato basalto, que vinha sendo manejado sob plantio direto por seis anos, com rotação de culturas, soja e milho, no verão, e aveia, ervilhaca e trigo, no inverno. Antes da semeadura da soja, no mês de novembro de 2004, realizou-se uma escarificação, utilizando-se um escarificador modelo Jumbo-Matic, equipado com cinco hastes de formato parabólico, espaçadas em $0,30 \mathrm{~m}$, discos de corte e rolo destorroador/nivelador, com atuação do implemento a uma profundidade média de $0,25 \mathrm{~m}$. Após a colheita da soja, em junho de 2005, semeou-se a cultura do trigo cultivar "Fundacep 30", com espaçamento entre linhas de $0,17 \mathrm{~m}$, que foi conduzido de acordo com as normas técnicas indicadas em REUNIÃO DA COMISSÃO SULBRASILEIRA DE PESQUISA DE TRIGO(2004). 
O delineamento experimental utilizado foi em blocos casualizados, em faixas, com sete repetições para cada tratamento. Os sistemas de manejo do solo estudados foram: plantio direto há seis anos (PD) e plantio direto escarificado (PDE), tendo-se nas subparcelas as profundidades e, nas parcelas, os sistemas de manejo do solo.

Amostras de solo com estrutura preservada, com de 50mm de altura e 50mm de diâmetro, foram retiradas para determinação das propriedades físicas do solo, antes da semeadura do trigo, na profundidade de $0,10 \mathrm{~m}$, e após a colheita do trigo, em intervalos de $0,05 \mathrm{~m}$ até a profundidade de $0,3 \mathrm{~m}$. Determinou-se a densidade e a porosidade total do solo segundo EMBRAPA (1997), enquanto que a porosidade de aeração foi obtida, subtraindo do volume total de poros o volume de poros cheios de água (LIBARDI, 2005). O volume de poros com água corresponde ao teor de água no solo em relação à base de volume. Esse valor foi obtido a partir das leituras do potencial de água no solo pelos sensores eletrônicos e o teor de água no solo obtido a partir das coletas de solo.

A densidade máxima foi determinada pelo teste Proctor normal, aplicando 560kPa de energia (NOGUEIRA, 1998) e a densidade relativa, obtida a partir da divisão entre a densidade do solo no campo e a densidade máxima, proposta por HAKANSSON (1990) e reapresentada por (KLEIN, 2006).

Para monitorar o potencial de água no solo durante todo ciclo da cultura do trigo, instalou-se, em cada sistema de manejo, numa única parcela, na profundidade de $0,10 \mathrm{~m}$, cinco sensores eletrônicos (Watermark), acoplados a um datalogger (Delta $\mathrm{T}$ devices), descrito e avaliado por KLEIN et al. (2004b), que realizou coleta e armazenamento dos dados em intervalos de uma hora, obtendo 2.678 leituras para cada sensor, durante o período de avaliação que foi de 22/07 a $11 / 11 / 2005$.

Amostras de solo com estrutura não preservada foram retiradas semanalmente na profundidade de $0,10 \mathrm{~m}$, mesma profundidade da instalação dos sensores, durante todo o ciclo da cultura do trigo para determinação do teor de água do solo.

A colheita do trigo foi realizada em subparcelas com $70 \mathrm{~m}^{2}$, com sete repetições em cada faixa. Avaliou-se o rendimento de grãos e os componentes de rendimento, tais como número de grãos por espiguetas e número de espiguetas por espiga de 10 plantas coletadas por sub parcela, bem como o peso de mil grãos e o peso hectolítrico dos grãos colhidos.

Os resultados das determinações físicas do solo e dos parâmetros da cultura do trigo foram submetidos a análise da variância, e quando essa foi significativa a 5\%, as médias das determinações físicas foram comparadas pelo teste de Tukey, e o rendimento de grãos e seus componentes de rendimento pelo teste t.

\section{RESULTADOS E DISCUSSÃO}

A escarificação promoveu a mobilização do solo, ocasionando aumento de volume e reduzindo significativamente a densidade do solo (Tabela 1). Na média dos manejos, o PDE apresentou uma densidade do solo 4,76\% inferior ao PD, concordando com BOLLER(1990) eKLEIN\& BOLLER(1995).Adensidade do solo mais elevada no PD deve-se ao não revolvimento do solo e ao tráfego de máquinas, muitas vezes com relação da área de contato do rodado com solo/peso da máquina inadequada (TORMENA, 1991; KLEIN \& BOLLER, 1995).

A porosidade total, espaço no qual ocorrem os fenômenos dinâmicos do solo, como era de se esperar, apresentou comportamento oposto ao da densidade, tendo o PDE apresentado volume de poros 4,97\% maior do que o PD.

A densidade máxima do solo (DMS), obtida pelo teste de Proctor normal, foi semelhante entre as profundidades e os manejos, ficando a média em torno de $1,56 \mathrm{Mg} \mathrm{m}^{-3}$, já a umidade ótima de compactação foi de $0,22 \mathrm{~kg} \mathrm{~kg}^{-1}$. A determinação da umidade ótima de compactação é uma informação muito importante, pois permite monitorar a umidade do solo na qual as condições para a compactação seriam ótimas, evitando nessa condição qualquer tipo de tráfego de máquinas em solos agrícolas.

A densidade relativa (DR) média do solo no PD foi de 0,90, enquanto no PDE, foi de 0,85 , apresentando diferença significativa entre os manejos e as profundidades. Comparando os manejos nas profundidades, o PD apresentou uma DR superior ao PDE na camada de 0 a $0,15 \mathrm{~m}$, indicando uma maior compactação do solo na camada superficial, camada essa que se concentra o maior volume do sistema radicular de plantas como o trigo (MERTEN \& MIELNICZUK, 1991).

Inúmeras tentativas têm sido feitas visando determinar a densidade relativa crítica ao desenvolvimento das plantas. KLEIN (2006), baseado na metodologia do intervalo hídrico ótimo (IHO) demonstrou que para um Latossolo Roxo (700 $\mathrm{gg}^{-1}$ argila) o valor da DR ótima foi de 0,715 e o valor crítico, 
Tabela 1 - Densidade do solo (DS), porosidade total (PT), densidade relativa (DR) e densidade máxima do solo (DMS) em função do manejo e da profundidade.

\begin{tabular}{|c|c|c|c|c|}
\hline \multirow[b]{2}{*}{ Profundidade } & \multicolumn{2}{|c|}{ DS } & \multicolumn{2}{|c|}{ PT } \\
\hline & PD & PDE & PD & PDE \\
\hline -------m------- & \multicolumn{2}{|c|}{----------Mg m'---------- } & \multicolumn{2}{|c|}{ - } \\
\hline $0,00-0,05$ & 1,316 Ab & 1,190 Bd & 0,512 Ba & 0,558 Аа \\
\hline $0,05-0,10$ & 1,445 Аа & 1,276 Bcd & $0,464 \mathrm{Bb}$ & 0,520 Aab \\
\hline $0,10-0,15$ & 1,418 Аа & 1,330 Bbc & 0,473 Bb & $0,506 \mathrm{Ab}$ \\
\hline $0,15-0,20$ & 1,420 Аa & 1,370 Aabc & 0,471 Aab & 0,492 Abc \\
\hline $0,25-0,25$ & 1,340 Bab & 1,443 Аа & 0,484 Aab & 0,464 Ac \\
\hline $0,25-0,30$ & 1,400 Aab & 1,380 Aab & 0,481 Аа & $0,488 \mathrm{Abc}$ \\
\hline Média & 1,398 A & 1,331 B & $0,481 \mathrm{~B}$ & 0,505 A \\
\hline \multirow[t]{2}{*}{ CV (\%) } & 4,18 & & 4,35 & \\
\hline & \multicolumn{2}{|c|}{ DMS } & \multicolumn{2}{|c|}{ DR } \\
\hline Profundidade & PD & PDE & PD & PDE \\
\hline -------m------- & \multicolumn{2}{|c|}{-----------Mg m ${ }^{-3}$} & & \\
\hline $0,00-0,05$ & 1,53 & 1,54 & 0,86 Аа & $0,77 \mathrm{Bd}$ \\
\hline $0,05-0,10$ & 1,58 & 1,58 & 0,92 Аа & 0,81 Bcd \\
\hline $0,10-0,15$ & 1,60 & 1,58 & 0,89 Аа & 0,84 Bbc \\
\hline $0,15-0,20$ & 1,58 & 1,59 & 0,90 Аа & 0,86 Aabc \\
\hline $0,25-0,25$ & 1,55 & 1,57 & 0,90 Аа & 0,92 Аа \\
\hline $0,25-0,30$ & 1,53 & 1,56 & 0,91 Аа & 0,88 Bab \\
\hline Média & 1,56 & 1,57 & 0,90 A & 0,85 B \\
\hline CV (\%) & & & 4,23 & \\
\hline
\end{tabular}

Médias seguidas pela mesma letra, maiúscula na horizontal e minúscula na vertical, para cada variável, não diferem estatisticamente pelo teste de Tukey $5 \%$ de significância.

$\mathrm{PD}=$ plantio direto há 6 anos, $\mathrm{PDE}$ = plantio direto escarificado.

sendo que o IHO=0 foi de 0,88. HAKANSSON (1990), trabalhando em solos da Suécia, encontrou máximo rendimento de cevada quando a DR se encontrava próxima a 0,87. FERRERAS et al. (2001) observaram, em um solo siltoso sob plantio, direto uma densidade relativa de 0,82 e 0,87 , respectivamente, nas camadas de 0-0,06m e 0,10-0,16m, e, no plantio direto escarificado, uma DR de 0,69 e 0,86, nas mesmas camadas, sendo que essa pequena diferença for encontrada na camada de 0,10-0,16m, refletindo drasticamente no rendimento da cultura de soja. CARTER (1990) destaca que, em plantio direto, parece haver um equilíbrio de $\mathrm{DR}$ próximo a 0,89 , condição que, no entanto, já afetaria o desenvolvimento das plantas. $\mathrm{O}$ valor de DR de 0,9, encontrado no PD nesse trabalho, parece corroborar aqueles resultados.

A análise dos resultados do potencial de água no solo durante todo o ciclo da cultura do trigo (Figura 1) permite observar que a escarificação do solo afetou a dinâmica da água no solo. A média dos cinco sensores eletrônicos instalados a $0,10 \mathrm{~m}$ de profundidade apresentou tendência semelhante entre os manejos. No entanto, com amplitudes distintas, sendo que o PDE apresentou tensões menores que o PD em apenas 262 horas do total de 2.678 horas monitoradas.

A determinação da curva característica de retenção da água no solo (Figura 1), determinada no campo com coletas periódicas de amostras de solo e relacionando com a tensão da água indicada pelo datalogger, permitiu determinar a umidade volumétrica no solo durante todo o período e, relacionando com a porosidade total, permitiu determinar o volume de poros livres de água (Figura 2).

Em função da maior porosidade do solo e das alterações provocadas na distribuição do diâmetro dos poros, a dinâmica da água foi alterada e o PDE apresentou uma maior porosidade de aeração em todo o período.

O efeito da compactação do solo sobre o desenvolvimento das plantas é dependente das condições climáticas vigentes. Em condições de deficiência hídrica, acentuam-se os problemas de limitação mecânica ao crescimento do sistema radicular, enquanto que em condições de excesso de precipitação, constatam-se problemas de deficiência

Ciência Rural, v.38, n.2, mar-abr, 2008. 

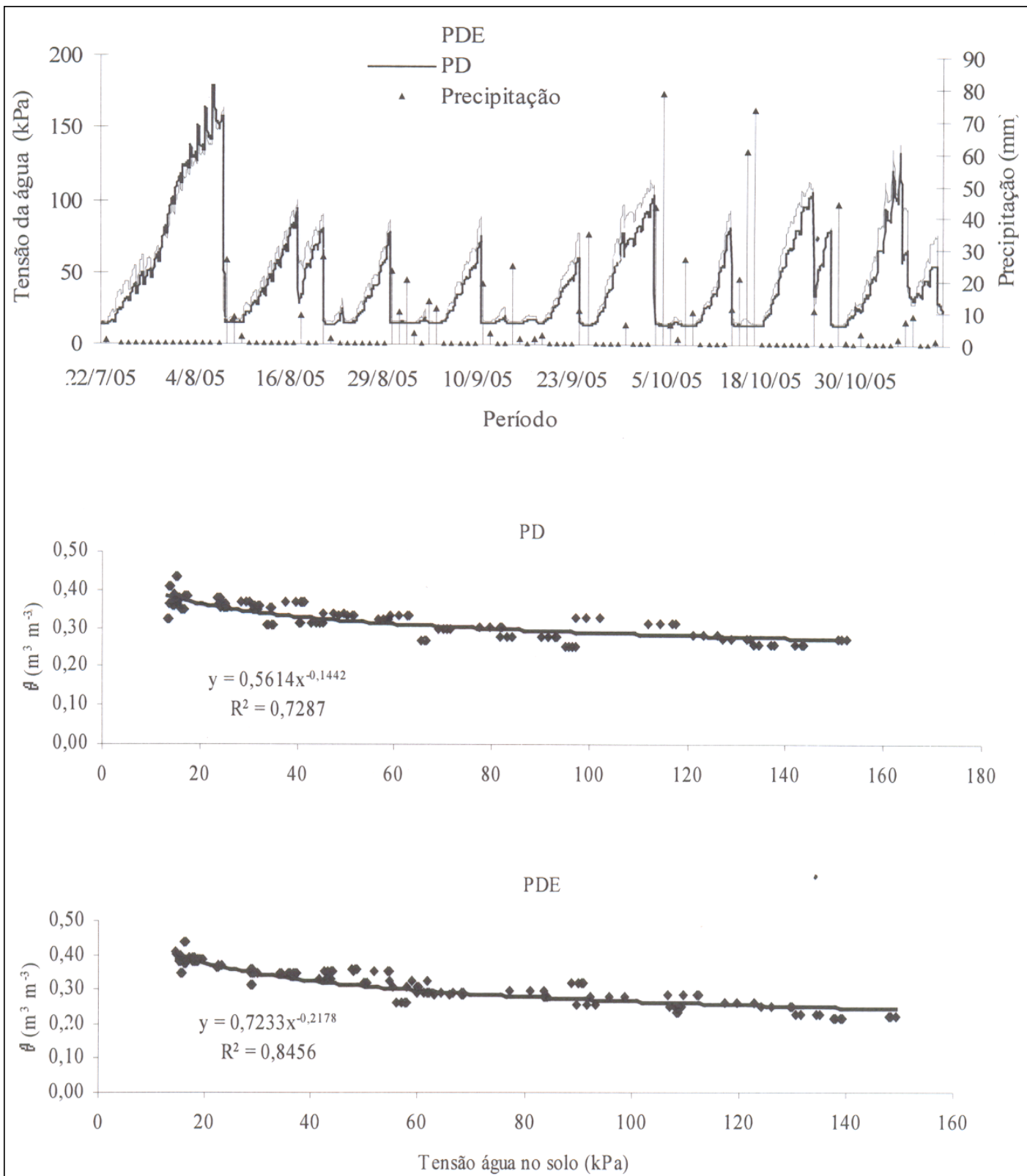

Figura 1 - Tensão da água no solo durante o ciclo da cultura do trigo em dois manejos de solo e precipitação ocorrida no período (EMBRAPA-Trigo) e umidade volumétrica em função da tensão da água no solo (sensores eletrônicos) no campo em dois manejos de solo (PD - Plantio direto e PDE = Plantio direto escarificado).

de aeração, com todas as conseqüências a ela relacionadas.

O inverno de 2005 foi muito chuvoso, com um grande número de ocorrências de chuvas com alta intensidade, durante o ciclo da cultura, sendo que de junho a novembro ocorreu precipitação total de $1.169 \mathrm{~mm}$, $17,58 \%$ superior à precipitação normal (964mm), o que acarretou níveis de aeração abaixo dos considerados limitantes, para uma adequada troca de gases. Os resultados demonstraram que durante 957 horas o PD apresentou volume de poros livres de água menor que $0,1 \mathrm{~m}^{3} \mathrm{~m}^{-3} \mathrm{e} 1.418 \mathrm{~h}$ menor que $0,15 \mathrm{~m}^{3} \mathrm{~m}^{-3}$, enquanto que $\mathrm{o}$ PDE apresentou em todo o período valores superiores a $0,15 \mathrm{~m}^{3} \mathrm{~m}^{-3}$ de poros livres de água. Esses dados demonstram que, no $\mathrm{PD}$, durante um grande período, a cultura do trigo se desenvolveu apartir condições de estresse do seu sistema radicular, uma vez que segundo ERICKSON (1982) e TORMENA et al.(1998), valores inferiores a $0,1 \mathrm{~m}^{3} \mathrm{~m}^{-3}$ de poros livres de água afetam o desenvolvimento e a produção das culturas. 


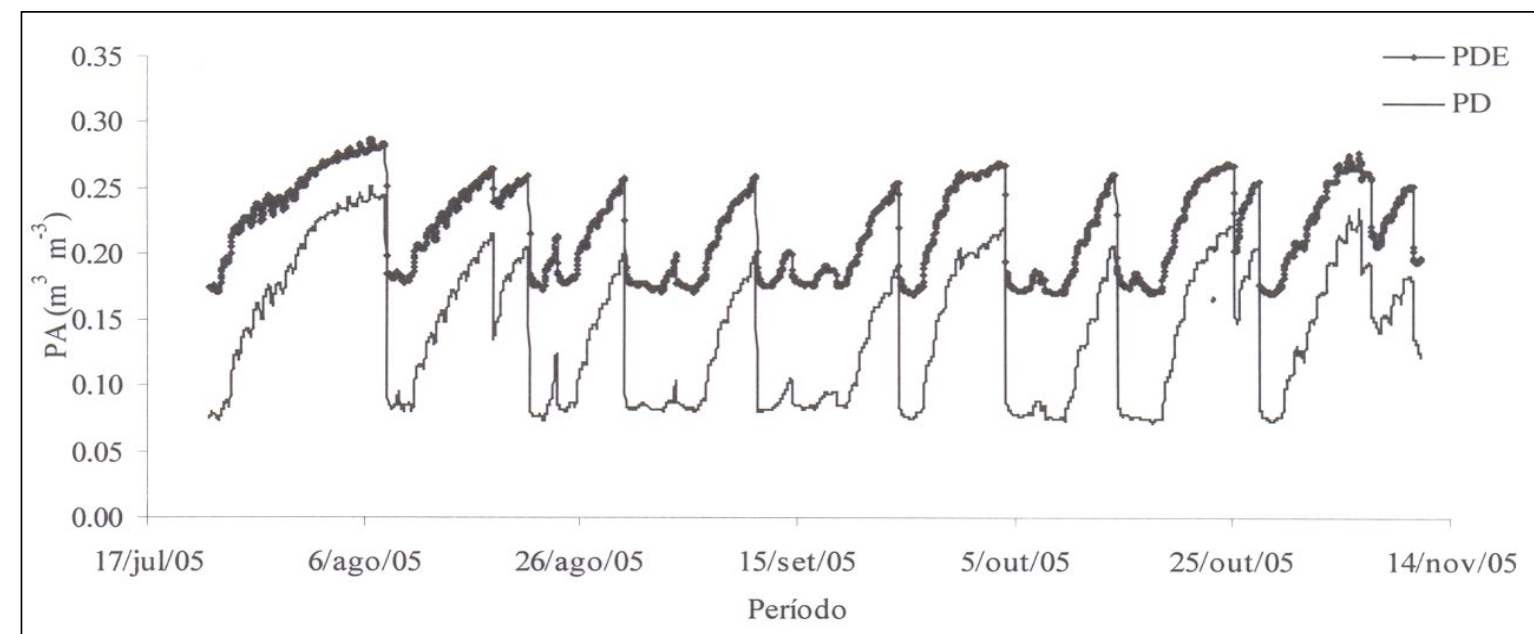

Figura 2 - Porosidade de aeração (PA) do solo durante o ciclo da cultura do trigo em dois manejos de solo (PD - Plantio direto há 6 anos e PDE = Plantio direto escarificado).

A cultura do trigo respondeu positivamente as alterações nas propriedades físicas do solo, provocadas pela escarificação, produzindo, em média, $682 \mathrm{~kg} \mathrm{ha}^{-1}$ a mais no PDE, comprovando o efeito positivo da escarificação do solo sobre o desenvolvimento e o rendimento da cultura do trigo. Dos componentes de rendimento, o número de grãos por espigueta, número de espiguetas por espiga e o peso hectolitro também foram significativamente maiores no PDE em relação ao PD (Tabela 2).

Outros autores obtiveram resultados semelhantes. SECCO \& REINERT (1997) observaram aumento de rendimento de grãos de milho no solo escarificado em relação ao PD. FERRERAS et al. (2001) obtiveram rendimento de soja 47,88 \% inferior no PD em relação ao PDE e atribuíram essa redução ao menor desenvolvimento radicular em função da resistência mecânica que afeta a absorção de água e nutrientes. KLEIN et al. (2004a) obtiveram rendimento de milho no PDE superior em $805 \mathrm{~kg} \mathrm{ha}^{-}$ ${ }^{1}$ em relação ao PD.
Esses dados corroboram com ERICKSON(1982) e STEPNIEWSKI et al. (1994) de que o preparo do solo é capaz de melhorar a difusão de gases no solo. Nesse caso, a escarificação do solo, após seis anos sob PD, foi capaz de melhorar as condições físico-hídricas do solo para o desenvolvimento das plantas.

\section{CONCLUSÕES}

A escarificação do solo sob sistema plantio direto há seis anos aumentou o rendimento de grãos de trigo semeado sete meses após a escarificação e diminuiu a densidade e a densidade relativa do solo, aumentando a porosidade total e a porosidade livre de água durante o ciclo da cultura do trigo.

\section{AGRADECIMENTOS}

À Fundação de Amparo à Pesquisa do Estado do Rio Grande do Sul (Fapergs) (Edital Procoredes 2, processo 05/ 1965.4), pelo financiamento do projeto. Ao Conselho Nacional de Desenvolvimento Científico e Tecnológico (CNPq), pelas bolsas de produtividade em pesquisa e de iniciação científica. Ao Pibic/UPF e Pibic/Fapergs, pelas bolsas de iniciação científica.

Tabela 2 - Rendimento de grãos de trigo (REND), número de grãos por espigueta (NGE), número de espiguetas por espiga (NEE), peso de mil sementes (PMS) e peso do hectolitro (PH), em função do manejo.

\begin{tabular}{lccccc}
\hline Manejo & REND $\left(\mathrm{kg} \mathrm{ha}^{-1}\right)$ & NGE & NEE & PMS (g) & PH \\
\hline PDE & $2478 \mathrm{a}$ & $2,13 \mathrm{a}$ & $14,36 \mathrm{a}$ & $34,67 \mathrm{a}$ & $74,47 \mathrm{a}$ \\
PD & $1796 \mathrm{~b}$ & $1,98 \mathrm{~b}$ & $12,68 \mathrm{~b}$ & $34,50 \mathrm{a}$ & $73,13 \mathrm{~b}$ \\
Média & 2137 & 2,05 & 13,52 & 34,58 & 73,80 \\
CV (\%) & 5,49 & 5,64 & 4,49 & 5,78 & 0,68 \\
\hline
\end{tabular}

Médias seguidas pela mesma letra minúscula, na vertical, não diferem significativamente pelo teste T a 5\% de significância.

Ciência Rural, v.38, n.2, mar-abr, 2008. 


\section{REFERÊNCIAS}

BOLLER, W. Desenvolvimento de complementos para semeadoras em solo sob preparo reduzido. 1990. $146 \mathrm{f}$. Dissertação (Mestrado em Engenharia Agrícola) - Curso de Pósgraduação em Engenharia Agrícola, Universidade Federal de Santa Maria.

CAMARA, R.K.; KLEIN, V.A. Escarificação em plantio direto como técnica de conservação do solo e da água. Revista Brasileira de Ciência do Solo, v.29, n.5, p.789-796. 2005a.

CAMARA, R.K.; KLEIN, V.A. Propriedades físico-hídricas do solo sob plantio direto escarificado e rendimento da soja. Ciência Rural, v.35, n.4, p.813-819, 2005b.

CARTER, M.R. Relative measures of soil bulk density to characterize compaction in tillage studies of fine loamy sands. Canadian Journal of Soil Science, v.70, p.425-433, 1990

EMPRESA BRASILEIRA DE PESQUISA AGROPECUÁRIA. Centro Nacional de Pesquisa de Solos. Manual de métodos de análise de solo. 2.ed. Rio de Janeiro, 1997. 212p.

ERICKSON, A.E. Tillage effects on soil aeration. Predicting tillage effects on infiltration. In: VAN DOREN, D.M. et al (Ed.). Predicting tillage effects on soil physical properties and processes. Madison: ASA, 1982. cap.6, p.91-104. (ASA. Special Publication, 44).

FERRERAS, L.A. et al. Parâmetros físicos del suelo en condiciones no perturbadas y bajo laboreo. Pesquisa Agropecuária Brasileira, v.36, p.161-170, 2001.

GLINSKI, J.; LIPIEC, J. Soil physical conditions and plant roots. Florida: CRC, 1990. 250p.

HAKANSSON, I. A method for characterizing the state of compactness of the plough layer. Soil \& Tillage Research, v.16, p.105-120, 1990

JONG VAN LIER, Q de. Oxigenação do sistema radicular: uma abordagem física. Revista Brasileira de Ciência do Solo, v.25, p.233-238, 2001

KLEIN, V.A. Propriedades físico-hídrico-mecânica de um latossolo roxo, sob diferentes sistemas de uso e manejo. 1998. 150f. Tese (Doutorado em Agronomia) Curso de Pós-graduação em Solos e Nutrição de Plantas, ESALQ/ Universidade de São Paulo.

KLEIN, V.A. Densidade relativa - um indicador da qualidade física de um Latossolo Vermelho. Revista de Ciências Agroveterinárias, v.5, p.26-32, 2006.

KLEIN, V.A.; BOLLER, W. Avaliação de diferentes métodos de manejos de solo e métodos de semeadura em áreas sob plantio direto. Ciência Rural, v.25, p.395-398, 1995.

KLEIN, V.A. et al. Avaliação de escarificadores e resposta da cultura do milho. Revista Brasileira de Ciência do Solo v.19, p.307-311, 1995.
KLEIN, V.A. et al. Rendimento de milho em plantio direto escarificado. In: REUNIÃO BRASILEIRA DE MANEJO E CONSERVAÇÃO DO SOLO E DA ÁGUA, 15., 2004, Santa Maria, RS. Resumos Expandidos... Santa Maria: SBCS, 2004a. CD-ROM.

KLEIN, V.A. et al. Avaliação de sensores eletrônicos de resistência elétrica e tensiômetros com transductores de tensão para determinação do potencial da água no solo. Revista de Ciências Agroveterinárias, v.3, n.2, p.80-86, 2004 b.

LIBARDI, P.L. Dinâmica da água no solo. Piracicaba: EDUSP, 2005. 335p.

MERTEN, G.H.; MIELNICZUK, J. Distribuição do sistema radicular e dos nutrientes em Latossolo Roxo, sob dois sistemas de preparo do solo. Revista Brasileira de Ciência do Solo, v.15, p.369-374, 1991.

NOGUEIRA, J.B. Mecânica dos solos. Ensaios de Laboratório São Carlos: EESC-USP, 1998. 248p.

REICHARDT, K.; TIMM, L.C. Solo, planta e atmosfera. Conceitos, processos e aplicações. Barueri: Manole, 2004 478p.

REUNIÃO DA COMISSÃO SUL-BRASILEIRA DE PESQUISA DE TRIGO, 2004, Passo Fundo, RS. Indicações... Passo Fundo: Comissão Sul-Brasileira de Pesquisa de Trigo, 2004. 152p.

SECCO, D.; REINERT, D.J. Efeitos imediato e residual de escarificadores em Latossolo Vermelho-escuro sob plantio direto. Engenharia Agrícola, v.16, p.52-61, 1997.

SOJKA, R.E. Stomatal closure in oxygen-stressed plants. Soil Science Society of America Journal, v.154, p.269-280, 1992.

STEPNIEWSKI, W. et al. Effects of compaction on soil aeration properties. In: SOANE, B.D.; OUWERKERK, C. (Ed.). Soil compaction in crop production. Amsterdam: Elsevier, 1994. p.167-189.

STRECK, E.V. et al. Solos do Rio Grande do Sul. Porto Alegre: EMATER/RS; UFRGS, 2002. 128p.

TORMENA, C.A. Resistência à penetração e porosidade em plantio direto influenciado por preparo préimplantação, calagem e tráfego. 1991. 155f. Dissertação (Mestrado em Agronomia) - Universidade Federal do Paraná.

TORMENA, C.A. et al. Caracterização do intervalo hídrico ótimo de um Latossolo Roxo sob plantio direto. Revista Brasileira de Ciência do Solo, v.22, p.573-581, 1998.

VIEIRA, M.L. Propriedades físico-hídrico-mecânicas do solo e rendimento de milho submetido a diferentes sistemas de manejo. 2006. 104f. Dissertação (Mestrado em Agronomia) - Curso de Pós-graduação em Agronomia, Universidade de Passo Fundo. 